\title{
Road Transportation Stress Promptly Increases Bovine Peripheral Blood Absolute NK Cell Counts and Cortisol Levels
}

\author{
Hiroshi ISHIZAKI ${ }^{1) *}$ and Yoshihiro KARIYA ${ }^{2)}$ \\ ${ }^{1)}$ Grazing System Research Team, National Institute of Livestock and Grassland Science, 768 Senbonmatsu, Nasushiobara, Tochigi 329- \\ 2793 and ${ }^{2)}$ Koibuchi College of Agriculture and Nutrition, 5965 Koibuchi-cho, Mito, Ibaraki 319-0323, Japan
}

(Received 4 October 2009/Accepted 3 February 2010/Published online in J-STAGE 16 February 2010)

\begin{abstract}
Livestock transportation effects on the number of circulating leukocytes have been reported. However, data related specifically to the relation between acute stress levels during transport and leukocyte differentiation, including lymphocyte subsets, are lacking. This study was undertaken to evaluate the distribution of peripheral blood leukocyte differential counts, CD25 lymphocytes and NK cells in calves subjected to truck transportation on different road types. Healthy Japanese Black calves were divided into three treatments: 1) those moved around in a mountainous area (Group M); 2) those moved around on flatland (Group F); and 3) those that were not transported (control). The plasma cortisol levels in Group $\mathrm{M}$ increased during transport. The increase was significantly higher at the end of transport than in the controls $(P<0.05)$; a slight increase was noted in Group F. Total leukocytes and the neutrophil to lymphocyte ratio in Group M were elevated with neutrophilia at $2 \mathrm{hr}$ post-transport $(P<0.05)$; the former levels remained higher than those in the controls for $4 \mathrm{hr}$. The numbers of lymphocytes, monocytes, eosinophils and CD25 lymphocytes remained unchanged throughout the observations. The number of circulating NK cells in Group M increased during transport and peaked shortly after transport $(P<0.05)$. Subsequent to these time points, the counts in Group F showed a trend toward elevation. The circulating NK cell counts were positively correlated with the plasma cortisol level during transport $(\mathrm{M}, r=0.755, P<0.0005 ; \mathrm{F}, r=0.653 ; P<0.005)$. These results suggest that circulating NK cells might be more rapidly mobilized than other leukocytes. Therefore, they might reflect acute stress levels in calves during road transportation.
\end{abstract}

KEY WORDS: calves, cortisol, NK cell, stress, truck transport.

J. Vet. Med. Sci. 72(6): 747-753, 2010

Livestock transportation is an acute physical stressor provoking an associated psychological response that is harmful whether viewed from either an animal welfare or economic perspective [38]. This stressor stimulates remarkable activation of the hypothalamic-pituitary-adrenal (HPA) axis, dramatically increasing the levels of glucocorticoids $[9,15$, 40]. It has also been found that most physical stressors induce activation of the sympathetic nervous system and catecholamines that influence the immune system [14, 32]. Consequently, these hormones are regarded as useful biomarkers in veterinary animals. Their stress-associated increases are generally viewed as responsible for immune depression. Furthermore, the elevation of glucocorticoids during the stress response engenders a complex of severe infectious respiratory diseases in cattle, presumably because of the altered immune function following transport [7, 26].

The finding that lymphocytes contain measurable concentrations of glucocorticoid and adrenergic receptors [1, 29] that are down-regulated in response to stress [28] suggests that alteration of the lymphoid compartment might play a major role in the immune system's response to stress. A recent study [30] demonstrated the effects of transportation stress on the proportion of circulating leukocytes expressing selected differentiated antigens in blood and notably found that circulating NK cells expanded in calves

\footnotetext{
* Correspondence to: IshizaKi, H., Grazing System Research Team, National Institute of Livestock and Grassland Science, 768 Senbonmatsu, Nasushiobara, Tochigi 329-2793, Japan. e-mail: hishizak@affrc.go.jp
}

transported $950 \mathrm{~km}$ in a truck. Meanwhile, it is well known that dexamethasone treatment and periparturient-induced stress dramatically alter IL-2R $\alpha$ (CD25) expression in bovine peripheral blood mononuclear cells (PBMC) [2, 22, 23]. However, few reports specifically describe the interplay between acute stress levels during transport and leukocyte differentiation, including these lymphocyte subsets. Data related to this subject are scarce.

The objective of this study was to evaluate the distribution of the lymphocyte subsets $\mathrm{CD} 25^{+}$(indicating the degree of $\mathrm{T}$ cell activation) and $\mathrm{NK}$ cells in the peripheral blood while comparing different blood leukocyte populations obtained from calves subjected to different stress levels during transport by truck for a short time over mountainous and flat roads.

\section{MATERIALS AND METHODS}

Animals and housing: Six clinically healthy Japanese Black steer calves (average initial body weight $=168.7 \pm$ $10.5 \mathrm{~kg}$ ) were used for this experiment. All animals were kept separately in a house with a stanchion 2 weeks prior to the experiment to facilitate their adaptation to the new environment. They were fed twice daily (09:00 and 16:00) with timothy grass hay ad libitum and $1.0 \mathrm{~kg}$ concentrate diet (TDN $>70 \%, \mathrm{CP}>10 \%$, on DM basis) each time, with $a d$ libitum access to fresh water and a mineral salt block during the in-house period, except on the morning of their transportation. The animals were randomly divided into three 
groups of two animals each. The three animal groups were allocated to the three treatments in a $3 \times 3$ Latin square design. The three treatment conditions were as follows: the animals were 1) transported and moved around a mountainous area along a winding and hilly route (Group M); 2) transported and moved around a flatland along a route with good-quality and less busy roads (Group F); or 3) neither loaded nor transported. The latter served as control subjects (Group C). This study was conducted at the Nasu Research Station (NRS), National Institute of Livestock and Grassland Science, Japan. The animals were cared for using acceptable practices approved by the National Institute of Livestock and Grassland Science Animal Care and Use Committee.

Transportation and blood sampling: The animals in Groups $\mathrm{M}$ and $\mathrm{F}$ were loaded onto two open-sided livestock trucks each $(>1.9 \times 4.2 \mathrm{~m})$, with no contact between them. The animals in Group M were shipped from the NRS (330 $\mathrm{m}$ above sea level) to and from the midpoint on a mountainside for a total roundtrip time of approximately $2 \mathrm{hr}(24 \mathrm{~km}$ point; $1,270 \mathrm{~m}$ ). The animals in Group $\mathrm{F}$ started from the NRS at the same time and were sent to and from a halfway point on non-mountainous, mostly level roads for the same amount of time ( $28 \mathrm{~km}$ point; $215 \mathrm{~m}$ ). Blood samples were obtained as soon as each transporter arrived at the midpoint in almost the same amount of elapsed time. After blood sampling, the animals were returned to the NRS. The control animals stayed at the NRS, where all were originally housed. Jugular blood, obtained by venipuncture, was collected from the transported animals either immediately before transport or at $1 \mathrm{hr}$ (except from Group C) or $2 \mathrm{hr}$ after transport and at 4, 6 and $24 \mathrm{hr}$, respectively, following 2, 4 and $22 \mathrm{hr}$ of recovery.

Total leukocyte and differential leukocyte counts: White blood cell counts for heparinized peripheral blood samples were determined using a blood cell counter (F-820; Sysmex Corp., Kobe, Japan). Thin blood smears for differential leukocyte population counts were air-dried and stained with Giemsa's solution. Altogether, 300 cells, including neutrophils, basophils, eosinophils, monocytes and lymphocytes, were counted under a microscope at $\times 400$ magnification; neutrophil to lymphocyte $(\mathrm{N} / \mathrm{L})$ ratio was also assessed.

Flow cytometry analysis: The primary mAbs used for this study were commercialized mouse mAbs (VMRD Inc., Pullman, WA, U.S.A., and AbD Serotec, Kidlington, U.K.) and were directed against the bovine homologs of interleukin-2 receptor alpha (CACT116A, CD25) [27] and NKp46 (AKS1, CD335) [35]. Then, $50 \mu l$ of each whole blood sample was incubated for $30 \mathrm{~min}$ with the same volume of primary antibody diluted adequately by PBS containing $1 \%$ FCS (F-PBS) for the bovine leukocyte surface antigens described above. Following cell washing with F-PBS, cell surface markers were visualized with $50 \mu l$ of a fluorescein Alexa 488-conjugated goat $\mathrm{F}(\mathrm{ab})^{2}$ to anti-mouse immunoglobulin G (1:400; A11017; Invitrogen Ltd., Paisley, U.K.) for $30 \mathrm{~min}$ in dark and chilled conditions. Following another wash, the cells were lysed and fixed using a com- mercial fixative (Immunoprep; Beckman Coulter Inc., Fullerton, CA, U.S.A.). They were analyzed using a flow cytometer (EPICS XL; Beckman Coulter Inc.); a live gate was set around the lymphocyte population obtained using the forward scatter/side scatter profile. A minimum of $1.0 \times$ $10^{4}$ events from the gated lymphocyte population were recorded. The results were presented as the percentage of cells positively stained and as the final calculated quantities of the respective populations.

Cortisol assay: Plasma cortisol levels were determined using a commercially available competitive binding assay kit (Cortisol Parameter Assay; R\&D Systems Inc., Minneapolis, MN, U.S.A.). Plasma samples were assayed at a 1:10 dilution; the minimum detection limit was $1.56 \mathrm{ng} / \mathrm{ml}$.

Statistical analyses: Analysis of variance for this study was performed using the MIXED procedure of SAS (Version 9.1.3; SAS Institute Japan Ltd., Tokyo, Japan) as a repeated measures analysis, with sampling time as the repeated value and animals as the subject. The model statement contained the fixed effects of treatment and time and the interaction of treatment $\times$ time. Multiple comparisons for each effect were performed using the PDIFF option in the LSMEAN statement. Results were considered significant at $P<0.05$. Pearson's correlation coefficients for cortisol levels and the circulating NK cell count were calculated during the transportation period using PROC CORR of the SAS software.

\section{RESULTS}

This experiment was conducted on three different days at two-week intervals during June-July 2006. The weather on these three days was rainy, but not windy. The ambient temperatures during loading on the three days were, respectively, 20.6, 23.7 and $21.5^{\circ} \mathrm{C}$, with temperatures during unloading of $21.0,24.5$ and $21.6^{\circ} \mathrm{C}$. Using routine clinical observations, the health conditions of the calves during the experimental period were monitored. The animals developed no clinical abnormalities such as depression or loss of appetite.

The plasma cortisol level in Group M increased immediately during transport and was significantly higher (50.8 \pm $6.7 \mathrm{ng} / \mathrm{ml})$ at the end of transport compared with the control calves $(14.7 \pm 6.7 \mathrm{ng} / \mathrm{ml}, P<0.05$; Fig. 1$)$. The level in Group $\mathrm{F}$ gradually increased during transport and was 32.1 $\pm 6.7 \mathrm{ng} / \mathrm{m} l$ at the end of transport ( $P=0.078 \mathrm{vs}$. controls). That in the control calves was unchanged. The increased cortisol levels during transport rapidly returned to normal after the transportation event.

Alterations in the leukocyte, lymphocyte, monocyte, neutrophil and eosinophil distributions and the N/L ratio are presented in Fig. 2. No significant change was found in lymphocytes and monocytes throughout the observation period. The numbers of total leukocytes and neutrophils and the N/L ratio for both transported groups were higher after transport. The total leukocyte counts in Group M were significantly higher $\left(139.5 \pm 13.1 \times 10^{2} / \mu l\right)$ at $2 \mathrm{hr}$ post- 


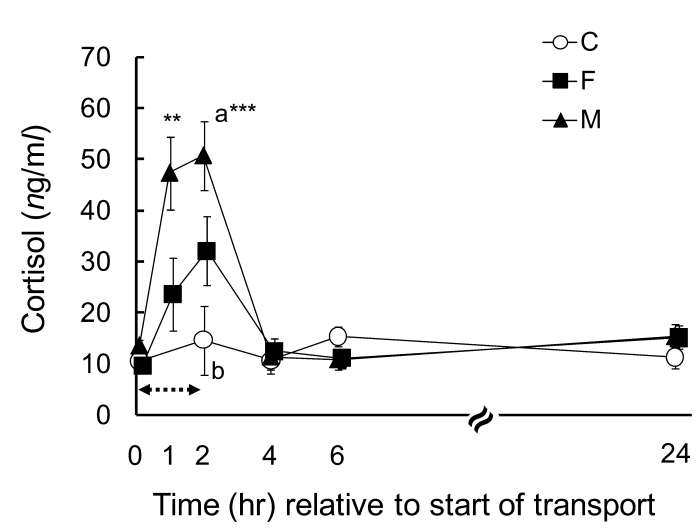

Fig. 1. Change in the plasma cortisol levels of transported and non-transported calves. $M(\mathbf{A} ; n=6)$, transported on a mountainous and winding road; $F(\boldsymbol{\square} ; \mathrm{n}=6)$, transported on a flat and non-winding road; $\mathrm{C}(\mathrm{O} ; \mathrm{n}=6)$, nontransported control. Bars represent the SEM of the least squares mean. Arrows indicate the transport duration (2 hr). a,b Means without common superscripts are significantly different $(P<0.05)$ at a given time point $* *, * * *$ Within each treatment, means are significantly different $(* * P<0.01, * * * P<0.005)$ from that at $0 \mathrm{hr}$.

unloading than in the controls $\left(111.3 \pm 13.1 \times 10^{2} / \mu l\right.$, $P<0.05)$ and remained high until $4 \mathrm{hr}$ post-unloading. However, the leukocyte counts in Group F (123.0 $\pm 13.1 \times 10^{2} /$ $\mu l$ ) did not differ significantly from the counts in Group $\mathrm{M}$ or those of the control calves. The neutrophil counts and levels of the N/L ratio in Group $M$ were high at $2 \mathrm{hr}$ posttransport; they differed significantly $\left(56.2 \pm 10.7 \times 10^{2} / \mu \mathrm{l}\right.$ and $1.11 \pm 0.2)$ from those in the controls $\left(27.2 \pm 10.7 \times 10^{2} /\right.$ $\mu l$ and $0.40 \pm 0.2, P<0.05)$, but not from those in Group $\mathrm{F}$ $\left(38.1 \pm 10.7 \times 10^{2} / \mu l\right.$ and $\left.0.45 \pm 0.2\right)$. These three measurements returned to the basal level 1 day after unloading. Although the eosinophil counts in Group F gradually declined because of transportation and reached a minimum level $\left(1.60 \pm 0.77 \times 10^{2} / \mu l\right.$ at $4 \mathrm{hr}$ post-transport $(P<0.05)$, those in Group M decreased significantly $\left(1.91 \pm 0.89 \times 10^{2} /\right.$ $\mu l)$ at $1 \mathrm{hr}$ after the start of transport $(P<0.05)$ and were at the minimum level $\left(1.79 \pm 0.77 \times 10^{2} / \mu l\right)$ at $4 \mathrm{hr}$ post-transport $(P<0.05)$ compared with the counts recorded before transport (Group F, $3.94 \pm 0.74 \times 10^{2} / \mu l$; Group M, $4.12 \pm$ $\left.0.74 \times 10^{2} / \mu l\right)$.

Figure 3 presents the variations in $\mathrm{CD} 25^{+}$lymphocytes and NK cells in peripheral blood after the start of transport. No significant change was observed in CD $25^{+}$lymphocytes in any of the three treatments. However, the number of circulating NK cells increased rapidly during transport and peaked shortly thereafter. Concurrently, the circulating NK cell counts in Group M increased immediately after the start of transport and exhibited a significant increase and peak $\left(11.3 \pm 1.1 \times 10^{2} / \mu l\right)$ in comparison with the controls $(4.1 \pm$ $\left.1.1 \times 10^{2} / \mu l, P<0.05\right)$, whereas those in Group F increased, but not remarkably $\left(6.4 \pm 1.1 \times 10^{2} / \mu l, P=0.079\right.$ vs. Group C). The NK cell counts in Group $\mathrm{C}$ remained unaltered. These elevated NK cell counts in the transported animals returned to the baseline value a day later.

A positive correlation was noted between the circulating NK cell counts and plasma cortisol levels during the transportation period, including the value before transport (Group M, $r=0.755, P<0.0005$; Group F, $r=0.653, P<0.005$; Fig. 4).

\section{DISCUSSION}

A change in the composition of peripheral blood cells reflects a physiological or pathophysiological response in animals. The transient increase in all leukocyte numbers associated with neutrophilia following transportation observed in this study demonstrates good agreement with prior studies using Bos taurus calf models [7, 25]. Stressful conditions are well known to stimulate the secretion of catecholamines and glucocorticoids, respectively, from the adrenal medulla and adrenal cortex [42]. The elevation of glucocorticoids results in lymphocyte destruction in the thymus cortex and extension of the neutrophil half-life [10, 41], resulting in an increased the $\mathrm{N} / \mathrm{L}$ ratio. Evidence from the literature suggests that the $\mathrm{N} / \mathrm{L}$ ratio increases in cattle after transport $[17,33]$. Consequently, this increase might be useful as an indicator of transportation stress, as is cortisol $[21,36]$. In the current study, the plasma cortisol levels in Group M during transport were up-regulated compared with those in Group F, suggesting that the animals transported around the mountainous area were more stressed by their transit. Furthermore, we considered that the drastic increase of plasma cortisol in Group M during the first half of the trip might be a reaction to a novel stimulus; however, the milder rise during the return trip was likely caused by adaptation to the environment. Grandin and Gallo [13] reported that minor losses of balance occur regularly during transport and that cattle quickly respond by shifting their footing to regain their balance. Eighty percents of losses of balance were accounted for by braking, gear changes and cornering. Concerning our study, Group F seemed to experience less frequent occurrence of imbalance than Group $M$ because of the good road conditions with less bumpy, winding road and fewer traffic jams. The N/L ratio in Group $M$ increased significantly after transport compared with that in Group F, suggesting that this ratio reflects greater stress levels on transit animals in a resting period subjected to a winding drive, even during a short-term trip. Circulating monocytes remained unaltered in this study. However, these results are not in agreement with results obtained by other investigators $[18,31]$, who reported monocytopenia with lymphopenia, which constitute typical features seen in leukograms following glucocorticoid administration or after their release because of stress. However, these features might not represent a frequent physiological response in cattle during shortterm road transportation. In the present study, circulating eosinophils started decreasing during transport, reaching the minimum level at $4 \mathrm{hr}$ after the end of the journey; they returned to the baseline level a day later. Eosinopenia is known to be induced by physical and emotional stress, 

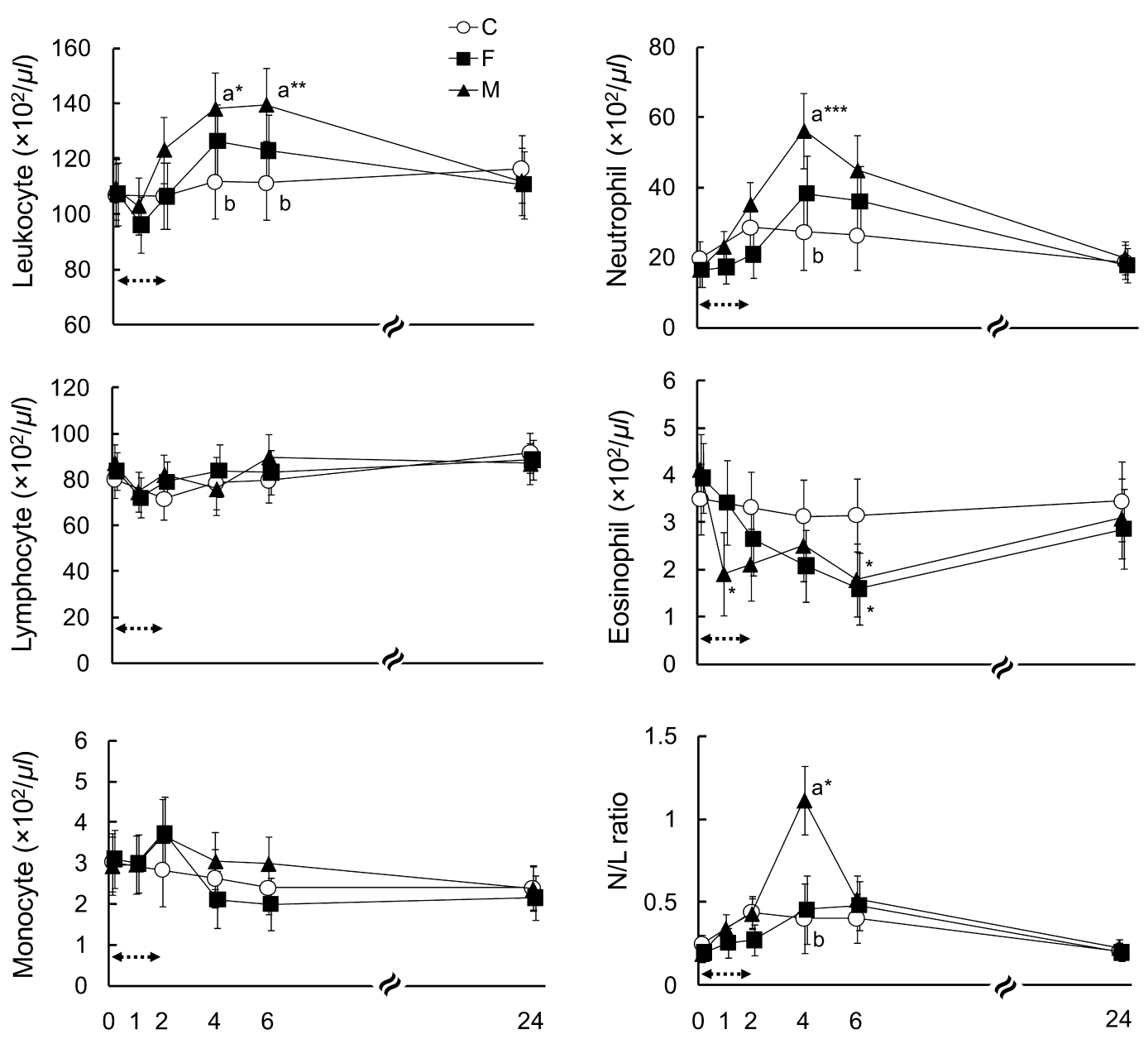

Time (hr) relative to start of transport

Fig. 2. Changes in the total and differential leukocyte counts and N/L ratio in the peripheral blood of transported and non-transported calves. $\mathrm{M}(\boldsymbol{\Delta} ; \mathrm{n}=6)$, transported on a mountainous and winding road; $\mathrm{F}(\boldsymbol{\square} ; \mathrm{n}=6)$, transported on a flat, non-winding road; $\mathrm{C}(\mathrm{O} ; \mathrm{n}=6)$, non-transported control. Bars represent the SEM of the least squares mean. Arrows indicate the transport duration $(2 \mathrm{hr})$. a,b Means without common superscripts are significantly different $(P<0.05)$ at a given time point. $*, * *, * * * W i t h i n$ each treatment, means are significantly different $(* P<0.05, * *$ $P<0.01, * * * P<0.005$ ) from that at $0 \mathrm{hr}$.

which is thought to be attributed to elevated levels of plasma epinephrine and cortisol [4]. Continuous release of corticosteroids or prolonged steroid therapy decreases eosinophil production.

In fact, IL-2R is unique among all growth factor receptors because it comprises three distinct membrane components: the $\alpha$ chain (IL-2R $\alpha$ ), $\beta$ chain (IL-2R $\beta$ ) and $\gamma$ chain (IL$2 \mathrm{R} \gamma$ ) [37]. Actually, IL-2R $\alpha$ (CD25) is present at low levels on resting $\mathrm{T}$ cells (with the exception of T regulatory cells), but is significantly up-regulated on activated T cells [39]. Dexamethazone treatment and $800 \mathrm{~km}$ transport stressinduced immunosuppression in calves involves decreased $\mathrm{CD} 25^{+}$expression in mitogen-stimulated PBMC culture [20], whereas in fresh PBMC preparations, that treatment increases the proportions of $\mathrm{CD} 25^{+}$cells $[2,23]$. Inconsis- tent findings were observed in this study as the CD25 $5^{+}$circulating lymphocytes were not significantly altered after transport, suggesting that the present trial term and distance might be shorter than those of the report of Lan et al. [20]. In addition, discrepancies between our findings and other studies may be explained by the possibility that the maximum effect of $\mathrm{CD} 25^{+}$expression of lymphocytes in dexamethazone-treated calves seems to be delayed-acting as compared with the case of transport-induced stress models.

The NK cells were initially defined as heterogeneous populations of large granular lymphocytes that can kill target cells spontaneously, suggesting enhancement of innate immunity. During the last decade, characterization of bovine NKp46, an activating receptor molecule, enabled more precise identification of bovine NK cells [35]. Interac- 

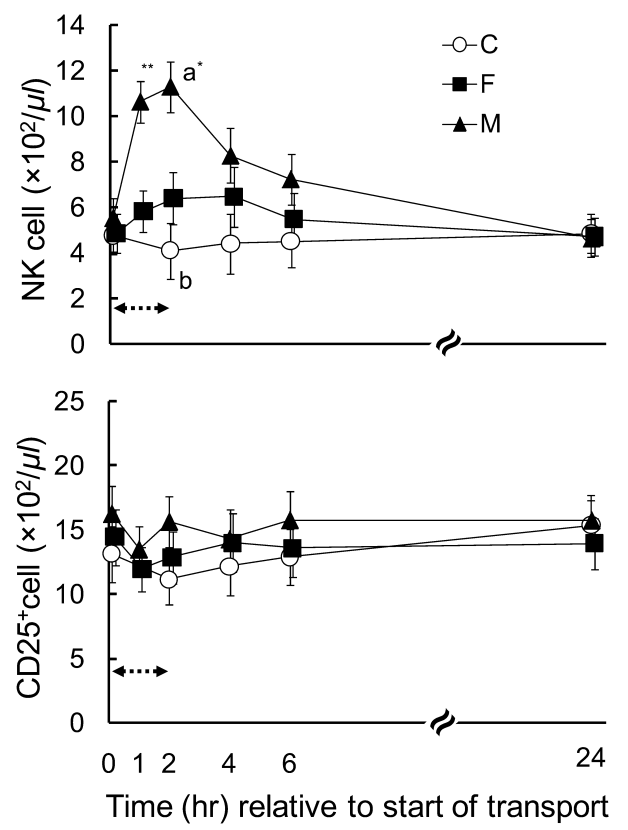

Fig. 3. Changes in the $\mathrm{CD} 25^{+}$lymphocyte and NK cell counts in the peripheral blood of transported and nontransported calves. Both cell types were observed quantitatively in the lymphocyte population using the forward scatter/side scatter profile obtained using flow cytometry. A minimum of 10,000 events from a gated lymphocyte population was acquired; results are presented as the percentage of cells that were positively stained, together with the finally calculated actual quantities of each population. $M(\mathbf{A} ; n=6)$, transported on a mountainous and winding road; $\mathrm{F}(\boldsymbol{\square} ; \mathrm{n}=6)$, transported on a flat and non-winding road; $\mathrm{C}(\mathrm{O} ; \mathrm{n}=6)$, non-transported control. Bars represent the SEM of the least squares mean. a,b Means without common superscripts are significantly different $(P<0.05)$ at a given time point. *,*Within each treatment, means are significantly different $(* P<0.05, * * P<0.01)$ from that at $0 \mathrm{hr}$.

tions between the immune system and HPA axis have been acknowledged for more than three decades. Cortisol, the most important endogenous glucocorticoid, is a potent inhibitor of the NK cell and its activity, as has been demonstrated for numerous in vitro models [5, 12]. However, conflicting results in human studies of the effect of cortisol exist in relation to in vivo and in vitro $\mathrm{NK}$ activity, showing increases, decreases, bimodal changes or no change. In the early phase of stress, psychological and physiological experimental acute stimuli induce a preponderant increase in circulating NK cells $[3,8,16,19,34]$. Moreover, the expansion of circulating bovine NK cells suggests transportstress-induced stimulation of the immune system [30]. Herein, we reported that the number of circulating NK cells during the early phase of transportation was notably elevated in Group $M$ compared with that in the controls, thereby revealing Group M to be the most stressful condition, as defined by the plasma cortisol levels. Slight eleva-

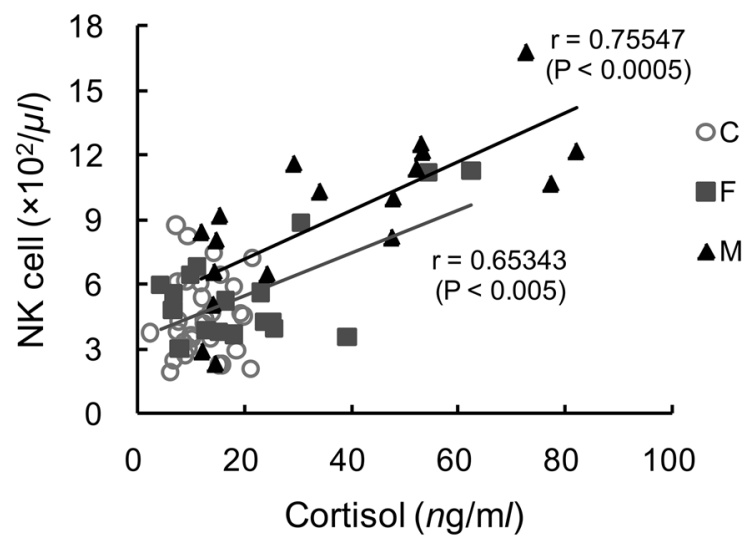

Fig. 4. Correlation between plasma cortisol levels and NK cell counts during transport. Solid lines represent regression lines (details in the figure). No significant correlation was found with the control.

tion was observed in Group F, a milder stress condition. Our results agreed with those of the above-described acute stimuli research. They suggest that circulating NK cells in the peripheral blood might be influenced by and might also more rapidly reflect the stress level during road transport than other immunological measures including the leukocyte count, neutrophil count or the N/L ratio, all of which showed significant changes in this study. However, interpretation of the mechanism of the early stimulation of NK cells found in this study is difficult. During the acute stress response, adrenaline or noradrenalin is secreted from sympathetic glands and activates NK cells located on the vascular endothelium via $\beta$-adrenergic receptors on their surfaces, resulting in an increase in the number of NK cells in peripheral blood [6, 11, 24]. Elevated blood pressure and increased blood flow elicited by sympathetic activity might increase the number of NK cells in the peripheral blood physically [6]. Although we did not measure catecholamines, further empirical research to examine them is warranted.

It remains unclear whether the reported results are limited to short-time transportation or if they can be generalized for other transportation systems. Further study using another cattle transport model (e.g., long duration, age variation, species and space allowance) is necessary for determining the relation between the number of NK cells and their activity in accordance with both sympathetic hormones and cortisol.

ACKNOWLEDGMENT(S). This work was financially supported in part by a Grant-in-Aid for Scientific Research (A) (No. 16208027) from the Ministry of Education, Culture, Sports, Science and Technology, Japan. We are grateful to the animal support staff of the Grassland Research Support Center, National Institute of Livestock and Grassland Science, for their care of the animals used for this study. 


\section{REFERENCES}

1. Abraham, G., Gottschalk, J. and Ungemach, F. R. 2004. Possible role of dexamethasone in sensitizing the beta-2-adrenergic receptor system in vivo in calves during concomitant treatment with clenbuterol. Pharmacology 72: 196-204.

2. Anderson, B. H., Watson, D. L. and Colditz, I. G. 1999. The effect of dexamethasone on some immunological parameters in cattle. Vet. Res. Commun. 23: 399-413.

3. Atanackovic, D., Brunner-Weinzierl, M. C., Kröger, H., Serke, S. and Deter, H. C. 2002. Acute psychological stress simultaneously alters hormone levels, recruitment of lymphocyte subsets, and production of reactive oxygen species. Immunol. Invest. 31: 73-91.

4. Beeson, P. B. and Bass, D. A. 1977. The eosinophil. pp. 1-269. In: Major Problems in Internal Medicine (Smith, L. N. J. ed.), W. B. Saunders, Philadelphia.

5. Benschop, R. J., Jabaaij, L., Oostveen, F. G., Vingerhoets, A. J., Kirschbaum, C., Duivenvoorden, H. J. and Ballieux, R. E. 1993. Psychobiological factors related to human natural killer cell activity and hormonal modulation of NK cells in vitro. Life Sci. 52: 1825-1834.

6. Benschop, R. J., Oostveen, F. G., Heijnen, C. J. and Ballieux, R. E. 1993. $\beta_{2}$-adrenergic stimulation causes detachment of natural killer cells from cultured endothelium. Eur. J. Immunol. 23: 3242-3247.

7. Blecha, F., Boyles, S. L. and Riley, J. G. 1984. Shipping suppresses lymphocyte blastogenic responses in Angus and Brahman $\times$ Angus feeder calves. J. Anim. Sci. 59: 576-583.

8. Brosschot, J. F., Benschop, R. J., Godaert, G. L., de Smet, M. B., Olff, M., Heijnen, C. J. and Ballieux, R. E. 1992. Effects of experimental psychological stress on distribution and function of peripheral blood cells. Psychosom. Med. 54: 394-406.

9. Buckham Sporer, K. R., Burton, J. L., Earley, B. and Crowe, M. A. 2007. Transportation stress in young bulls alters expression of neutrophil genes important for the regulation of apoptosis, tissue remodeling, margination, and anti-bacterial function. Vet. Immunol. Immunopathol. 118: 19-29.

10. Butcher, S. K. and Lord, J. M. 2004. Stress responses and innate immunity: aging as a contributory factor. Aging Cell 3: 151-160.

11. Farag, N. H., Nelesen, R. A., Dimsdale, J. E., Loredo, J. S. and Mills, P. J. 2002. The effects of acute psychological stress on lymphocyte adhesion molecule expression and density in cardiac versus vascular reactors. Brain Behav. Immun. 16: 411420.

12. Gatti, G., Masera, R. G., Pallavicini, L., Sartori, M. L., Staurenghi, A., Orlandi, F. and Angeli, A. 1993. Interplay in vitro between ACTH, $\beta$-endorphin, and glucocorticoids in the modulation of spontaneous and lymphokine-inducible human natural killer (NK) cell activity. Brain Behav. Immun. 7: 16-28.

13. Grandin, T. and Gallo, C. 2007. Cattle transport. pp. 134-154. In: Livestock Handling and Transport, 3rd ed. (Grandin, T. ed.), CABI Publishing, Wallingford.

14. Griffin, J. F. T. and Thomson, A. J. 1998. Farmed deer: a large animal model for stress. Domest. Anim. Endocrinol. 15: 445456.

15. Gupta, S., Earley, B. and Crowe, M. A. 2007. Effect of 12-hr road transportation on physiological, immunological and haematological parameters in bulls housed at different space allowances. Vet. J. 173: 605-616.

16. Isowa, T., Ohira, H. and Murashima, S. 2006. Immune, endocrine and cardiovascular responses to controllable and uncon- trollable acute stress. Biol. Psychol. 71: 202-213.

17. Kegley, E. B., Spears, J. W. and Brown, T. T. J. 1997. Effect of shipping and chromium supplementation on performance, immune response, and disease resistance of steers. J. Anim. Sci. 75: 1956-1964.

18. Kelley, K. W., Osborne, C. A., Evermann, J. F., Parish, S. M. and Hinrichs, D. J. 1981. Whole blood leukocyte vs. separated mononuclear cell blastogenesis in calves: time-dependent changes after shipping. Can. J. Comp. Med. 45: 249-258.

19. Kimura, K., Isowa, T., Ohira, H. and Murashima, S. 2005. Temporal variation of acute stress responses in sympathetic nervous and immune systems. Biol. Psychol. 70: 131-139.

20. Lan, H. C., Reddy, P. G., Chambers, M. A., Walker, G., Srivastava, K. K. and Ferguson, J. A. 1995. Effect of stress on interleukin-2 receptor expression by bovine mononuclear leukocytes. Vet. Immunol. Immunopathol. 49: 241-249.

21. McFarlane, J. M., Morris, G. L., Curtis, S. E., Simon, J. and McGlone, J. J. 1988. Some indicators of welfare of crated veal calves on three dietary iron regimens. J. Anim. Sci. 66: $317-$ 325.

22. Meglia, G. E., Johannisson, A., Agenas, S., Holtenius, K. and Waller, K. P. 2005. Effects of feeding intensity during the dry period on leukocyte and lymphocyte sub-populations, neutrophil function and health in periparturient dairy cows. Vet. J. 169: $376-384$.

23. Menge, C. and Dean-Nystrom, E. A. 2008. Dexamethasone depletes $\gamma \delta \mathrm{T}$ cells and alters the activation state and responsiveness of bovine peripheral blood lymphocyte subpopulations. J. Dairy Sci. 91: 2284-2298.

24. Mills, P. J., Goebel, M., Rehman, J., Irwin, M. R. and Maisel, A. S. 2000. Leukocyte adhesion molecule expression and $\mathrm{T}$ cell naive/memory status following isoproterenol infusion. $J$. Neuroimmunol. 102: 137-144.

25. Murata, H. and Hirose, H. 1990. Impairment of lymphocyte blastogenesis in road-transported calves observed with a whole blood culture technique. Jpn. J. Vet. Res. 52: 183-185.

26. Murata, H., Takahashi, H. and Matsumoto, H. 1987. The effects of road transportation on peripheral blood lymphocyte subpopulations, lymphocyte blastogenesis and neutrophil function in calves. Br. Vet. J. 143: 166-174.

27. Naessens, J., Sileghem, M., MacHugh, N., Park, Y. H., Davis, W. C. and Toye, P. 1992. Selection of BoCD25 monoclonal antibodies by screening mouse $\mathrm{L}$ cells transfected with the bovine p55-interleukin-2 (IL-2) receptor gene. Immunology 76: 305-309.

28. Odore, R., D’Angelo, A., Badino, P., Bellino, C., Pagliasso, S. and Re, G. 2004. Road transportation affects blood hormone levels and lymphocyte glucocorticoid and $\beta$-adrenergic receptor concentrations in calves. Vet. J. 168: 297-303.

29. Preisler, M. T., Weber, P. S., Tempelman, R. J., Erskine, R. J., Hunt, H. and Burton, J. L. 2000. Glucocorticoid receptor expression profiles in mononuclear leukocytes of periparturient Holstein cows. J. Dairy Sci. 83: 38-47.

30. Riondato, F., D'Angelo, A., Miniscalco, B., Bellino, C. and Guglielmino, R. 2008. Effects of road transportation on lymphocyte subsets in calves. Vet. J. 175: 364-368.

31. Ruppanner, R., Norman, B. B., Adams, C. J., Addis, D. G., Lofgreen, G. P., Clark, J. G. and Dunbar, J. R. 1978. Metabolic and cellular profile testing in calves under feedlot conditions: blood cellular components - reference values and changes over time in feedlot. Am. J. Vet. Res. 39: 851-854.

32. Sanders, V. M. and Straub, R. H. 2002. Norepinephrine, the $\beta$ adrenergic receptor, and immunity. Brain Behav. Immun. 16: 
290-332.

33. Schaefer, A. L., Jones, S. D. and Stanley, R. W. 1997. The use of electrolyte solutions for reducing transport stress. J. Anim. Sci. 75: 258-265.

34. Schedlowski, M., Jacobs, R., Stratmann, G., Richter, S., Hädicke, A., Tewes, U., Wagner, T. O. F. and Schmidt, R. E. 1993. Changes of natural killer cells during acute psychological stress. J. Clin. Immunol. 13: 119-126.

35. Storset, A. K., Slettedal, I. O., Williams, J. L., Law, A. and Dissen, E. 2003. Natural killer cell receptors in cattle: a bovine killer cell immunoglobulin-like receptor multigene family contains members with divergent signaling motifs. Eur. J. Immunol. 33: 980-990.

36. Stull, C. L. and McDonough, S. P. 1994. Multidisciplinary approach to evaluating welfare of veal calves in commercial facilities. J. Anim. Sci. 72: 2518-2524.

37. Taniguchi, T. and Minami, Y. 1993. The IL-2/IL-2 receptor system: a current overview. Cell 73: 5-8.
38. Van de Water, G., Verjans, F. and Geers, R. 2003. The effect of short distance transport under commercial conditions on the physiology of slaughter calves: $\mathrm{pH}$ and colour profiles of veal. Livest. Prod. Sci. 82: 171-179.

39. Waldmann, T., Tagaya, Y. and Bamford, R. 1998. Interleukin2, interleukin-15, and their receptors. Int. Rev. Immunol. 16: 205-226.

40. Yagi, Y., Shiono, H., Chikayama, Y., Ohnuma, A., Nakamura, I. and Yayou, K. 2004. Transport stress increases somatic cell counts in milk, and enhances the migration capacity of peripheral blood neutrophils of dairy cows. J. Vet. Med. Sci. 66: 381387.

41. Zhang, X., Moilanen, E. and Kankaanranta, H. 2001. Beclomethasone, budesonide and fluticasone propionate inhibit human neutrophil apoptosis. Eur. J. Pharmacol. 431: 365-371.

42. Zuri, I., Gottreich, A. and Terkel, J. 1998. Social stress in neighboring and encountering blind mole-rats (Spalax ehrenbergi). Physiol. Behav. 64: 611-620. 